\title{
Earliest Jurassic patellogastropod, vetigastropod, and neritimorph gastropods from Luxembourg with considerations on the Triassic-Jurassic faunal turnover
}

\author{
Stefano Monari, Mara Valentini, and Maria Alessandra Conti \\ Acta Palaeontologica Polonica 56 (2), 2011: 349-384 doi: http://dx.doi.org/10.4202/app.2010.0098
}

The Hettangian to earliest Sinemurian Vetigastropoda, Patellogastropoda, and Neritimorpha housed in the National Museum of Natural History of Luxembourg are studied. Most of the species comes from the Luxembourg Sandstone Formation. This deposit formed along the southern margin of the London-Brabant-Ardennes Landmass, in a region that during the earliest Jurassic constituted a seaway connecting the ParisBasin with the epicontinental seas of the Netherlands and northern Germany. The systematic analysis revealed high diversity of the studied fauna; we identified twenty-two species, eleven genera, nine families, and six superfamilies. A new genus, Meiersia gen. nov., and three new species, Anodomaria schroederi sp. nov., Meiersia disarmata sp. nov., and Spirocirrus weisi sp. nov. are described. The fauna is dominated by pleurotomarioideans representing the genera Ptychomphalus, Pleurotomaria , and Trochotoma, and by the patellogastropod genus Scurriopsis both in number of species and specimens. The neritimorph genus Neridomus is also well represented. Among the accessory taxa, Anodomaria and Spirocirrus first appeared in the Late Hettangian of the Luxembourg area. Most of these genera show a species radiation in the Early Jurassic and are distributed over the western European epicontinental shelf, probably favoured by an east to westmarine transgression which influenced wide areas from the basins of the northern Germany to the Paris Basin through the Luxembourg seaway. The evolutionary and palaeobiogeographical data demonstrate that this radiation was already considerably advanced in the Late Hettangian. This suggests that the recovery of the gastropod diversity after the end-Triassic crisis was relatively fast in western Europe.

Key words: Gastropoda, end-Triassic crisis, palaeobiogeography, Early Jurassic, Hettangian, Luxembourg Sandstone Formation, Paris Basin.

Stefano Monari [stefano.monari@unipd.it], Dipartment of Geosciences, University of Padua, via Gradenigo 6, 35131 Padua, Italy. Mara Valentini [mara.valentini@ uniroma1.it ] and Maria Alessandra Conti [sandra.conti@uniroma1.it], Department of Earth Sciences, University of Rome "La Sapienza", P.le Aldo Moro 5, I-00185 Rome, Italy. 
This is an open-access article distributed under the terms of the Creative Commons Attribution License (for details please see creativecommons.org), which permits unrestricted use, distribution, and reproduction in any medium, provided the original author and source are credited.

Farf Full text $(2,568.8 \mathrm{kB})$ 